\title{
AIMHI NT ‘Mental Health Story Teller Mob’: Developing stories in mental health
}

\author{
Tricia Nagel $^{1}$ and Carolyn Thompson ${ }^{2}$
}

1. Consultant Psychiatrist, Top End Mental Health Services, Casuarina, Northern Territory, Australia; Senior Lecturer, Flinders University, Adelaide, South Australia and James Cook University, Townsville, Queensland, Australia

2. Menzies School of Health Research, Darwin, Northern Territory, Australia

\begin{abstract}
The Australian Integrated Mental Health Initiative in the Northern Territory is one of a number of sites funded by the National Health and Medical Research Council. The project has been working with Aboriginal Mental Health Workers (AMHWs), and the Top End Division of General Practice (TEDGP) to adapt mental health information to the Aboriginal and Torres Strait Islander context through development of mental health stories. The stories focus on personal strengths and family support, and use local artwork and images, local language, metaphors and music. The concepts have been incorporated into service provider training and psychoeducation resources in the Northern Territory. Development and evaluation of mental health literacy initiatives is important in the context of high rates of mental illness and burden of disease in the Aboriginal and Torres Strait Islander community.
\end{abstract}

\section{Keywords}

Aboriginal and Torres Strait Islander mental health, Indigenous, remote, mental health literacy

\section{Background}

The World Health Organization has highlighted that the proportion of the global burden of disease attributable to mental illnesses is high, and expected to rise. Neuropsychiatry conditions together account for about $11 \%$ of the global burden of disease. It predicts that these problems will place a greater burden on vulnerable groups such as people living in absolute and relative poverty, and those coping with chronic diseases (World Health Organization, 2006). This prediction has direct implications for Aboriginal and Torres Strait Islander people in Australia. A recent Australian Bureau of Statistics and Australian Institute of Health and Welfare report confirms that not only do Aboriginal and Torres Strait Islander Australians have a higher prevalence of most types of health conditions and die at almost three times the rate of non-
Indigenous males and females, they were twice as likely to be admitted to hospital for mental illness, and there were almost three times as many deaths associated with mental illness as would be expected, based on the rates for nonIndigenous Australians (Australian Bureau of Statistics, 2005). In the Northern Territory (NT), also, there are high numbers of Aboriginal and Torres Strait Islander hospital admissions for psychiatric illness, and escalating substance misuse, self-harm and suicide rates. The Indigenous hospital separation rate per 100,000 in the Top End in 2002-2003 was nearly twice the rate for non-indigenous people, whilst NT age adjusted suicide rates more than doubled in the last two decades (Clough, D'Abbs, Parker et al., 2004; Condon, Warman \& Arnold, 2001; Li, Measey \& Parker, 2004; McLennan \& Khavarpour, 2004; Nagel, 2005a, 2006b).

Contact: $\quad$ Dr Tricia Nagel, MBBS, FRANZCP, Consultant Psychiatrist, Top End Mental Health Services, PO Box 40596 Casuarina, Northern Territory, Australia 0811 trish.nagel@nt.gov.au

Citation: $\quad$ Nagel, T. \& Thompson, C. (2007). AIMHI NT 'Mental Health Story Teller Mob’: developing stories in mental health Australian e-Journal for the Advancement of Mental Health, 6(2), www.auseinet.com/journal/vol6iss2/nagel.pdf

Published by: Australian Network for Promotion, Prevention and Early Intervention for Mental Health (Auseinet) www.auseinet.com/journal Received 3 February 2007; Revised 5 May 2007; Accepted 5 May 2007 
Client and family psychoeducation are important psychosocial strategies for mental health treatment, and are recommended in best practice guidelines for treatment and relapse prevention (Australian Health Ministers Advisory Council's National Mental Health Working Group, 1996; McGorry, Killackey, Elkins et al., 2003; Rickwood, 2002). Furthermore, there is increasing recognition that psychoeducation and promotion of mental health literacy in the broader community will be an important additional strategy for addressing the increasing burden of mental illness (Jorm, Korten, Jacomb et al., 1997). Aboriginal and Torres Strait Islander Australians, however, will often require a cross cultural translation of such interventions, as they speak different languages, use different communication styles and have different understandings of health and identity (Cass, Lowell, Christie et al., 2002; Eades, 2005; Trudgen, 2000). The approach to sharing mental health information must also take a different path. Culturally appropriate health promotion strategies will acknowledge and promote cultural identity, and link with traditional ways of telling important stories within the community (Emotional and Social Wellbeing Working Party, 2003; Kirmayer, Simpson \& Cargo, 2003; Murray, Bell, Elston et al., 2002).

The Australian Integrated Mental Health Initiative in the Northern Territory (AIMHI NT) is one location of a multi site National Health and Medical Research Council funded project that, in partnership with North Queensland (NQ), has been focussed on developing strategies to improve outcomes for remote Aboriginal and Torres Strait Islander people with mental illness. In 2003 a remote service provider survey in the NT (Nagel, 2006b) revealed that strategies for education of clients and carers were limited, and culturally appropriate information resources were few (Nagel, 2005a). One of the AIMHI NT goals has been to develop culturally appropriate resources for mental health literacy in the remote setting, which might enhance a two way understanding of mental illness (Nagel, 2006a). This goal led to development of a central component of AIMHI NT activities since 2003 the story telling project.

\section{Design of the story telling project}

The Top End of the Northern Territory includes coastal and island communities as well as inland bush and desert regions. The AIMHI NT project aimed to develop resources that resonated with the experience of the community and remote service providers, especially the Aboriginal Mental Health Workers (AMHWs) of the NT. We needed to capture the local perception of mental illness, and to present our information in a way that was easily understood. We also needed to overcome stigma related to mental illness, and negative attitudes toward research, in order to access the remote communities in which our target population lived. Hence the project needed to gather a research team that was culturally appropriate, develop cross cultural community consultation tools, and develop cross cultural education resources. The core AIMHI NT research team comprises four investigators. The Chief Investigator is a psychiatrist who has lived and worked in the NT for more than twenty years. The three Aboriginal associate investigators are: an AMHW of Walpiri-Gurindji (Katherine West region of NT) heritage, who works as a researcher and a part time service provider, an Aboriginal research officer who is a Larrakiah (Darwin area) traditional owner, and an Indigenous research officer who is of Gurindji/Walpiri and Anmatjerre/Arrente heritage.

The team works with a local steering committee, Indigenous reference group and three important partnerships: Top End Divison of General Practice Mental Health Worker Program, the Tiwi Islands mental health team, and the Department of Health and Community Services. The AIMHI team was given the title 'AIMHI Mental Health Story Teller Mob' in 2003, and developed a logo that incorporated desert and coastal artwork. This combination of artwork was important in order to convey the message to local Indigenous people that we were developing stories for desert as well as 'saltwater' (coastal) people. This paper presents the role of story telling in the AIMHI NT project in the course of three stages of the project: the consultation phase, the collaboration phase (developing 


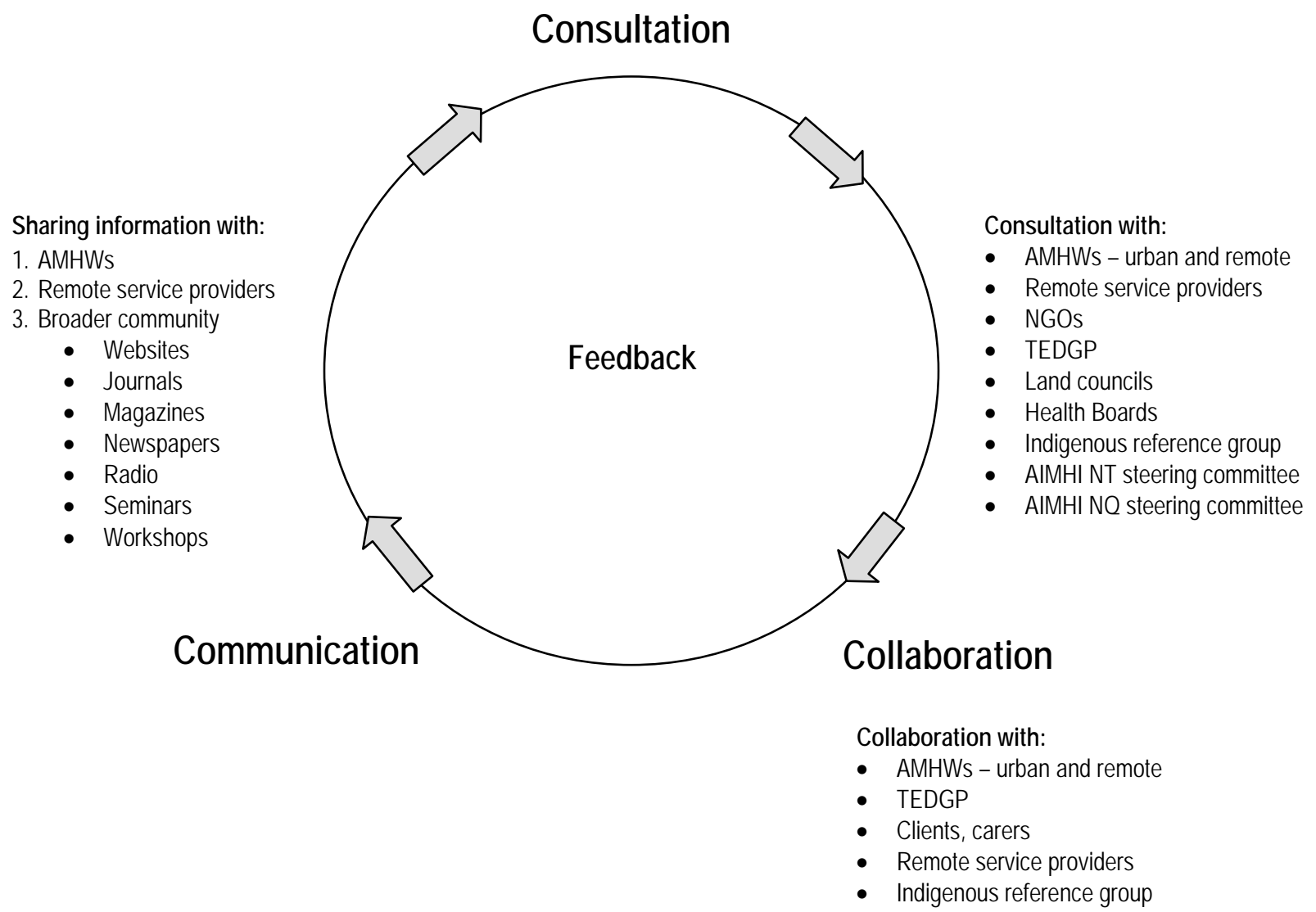

Figure 1. AIMHI consultation and collaboration with stakeholders and communication strategies 2003-2006

mental health promotion resources), and the communication phase (sharing those resources with the community, clients, carers, and service providers) (see Figures 1 and 2).

\section{Urban consultation and collaboration}

The AIMHI research team consulted with a range of non-government and government organisations in the first 12 months of the AIMHI project, including health boards and land councils. The eventual outline of the story we wanted to tell was in four parts: 'what keeps me strong', 'what takes my strength away', 'what happens to me when I am sick', and 'what helps to get me well'. We visited remote communities hundreds of kilometres from our base in Darwin - Kalano, Nguiu, Groote Eylandt, Yirrkala, Numbulwar, and a wide range of urban services. We were advised by stakeholders to use pictures instead of words, to use slow, plain English instead of complex English, and to use
Aboriginal and Torres Strait Islander voices and language. We were shown examples of different styles of presentation which people found easier to understand. The consultation tools began with PowerPoint presentations, but later included the new software MARVIN (Messaging Architecture for the Retrieval of Versatile Information \& News). This software allowed the project to animate the PowerPoint presentations using Aboriginal and Torres Strait Islander characters and to overlay language and music. We presented the early stories to the AIMHI NT Indigenous reference group and steering committee, to local Aboriginal and Torres Strait Islander groups and non-government organisations (NGOs), and to conferences and workshops. The research team also gathered evidence about NT Aboriginal and Torres Strait Islander mental illness from surveys, admission data, and literature review (Nagel, 2005a). Each presentation became another opportunity 


\section{Consultation}

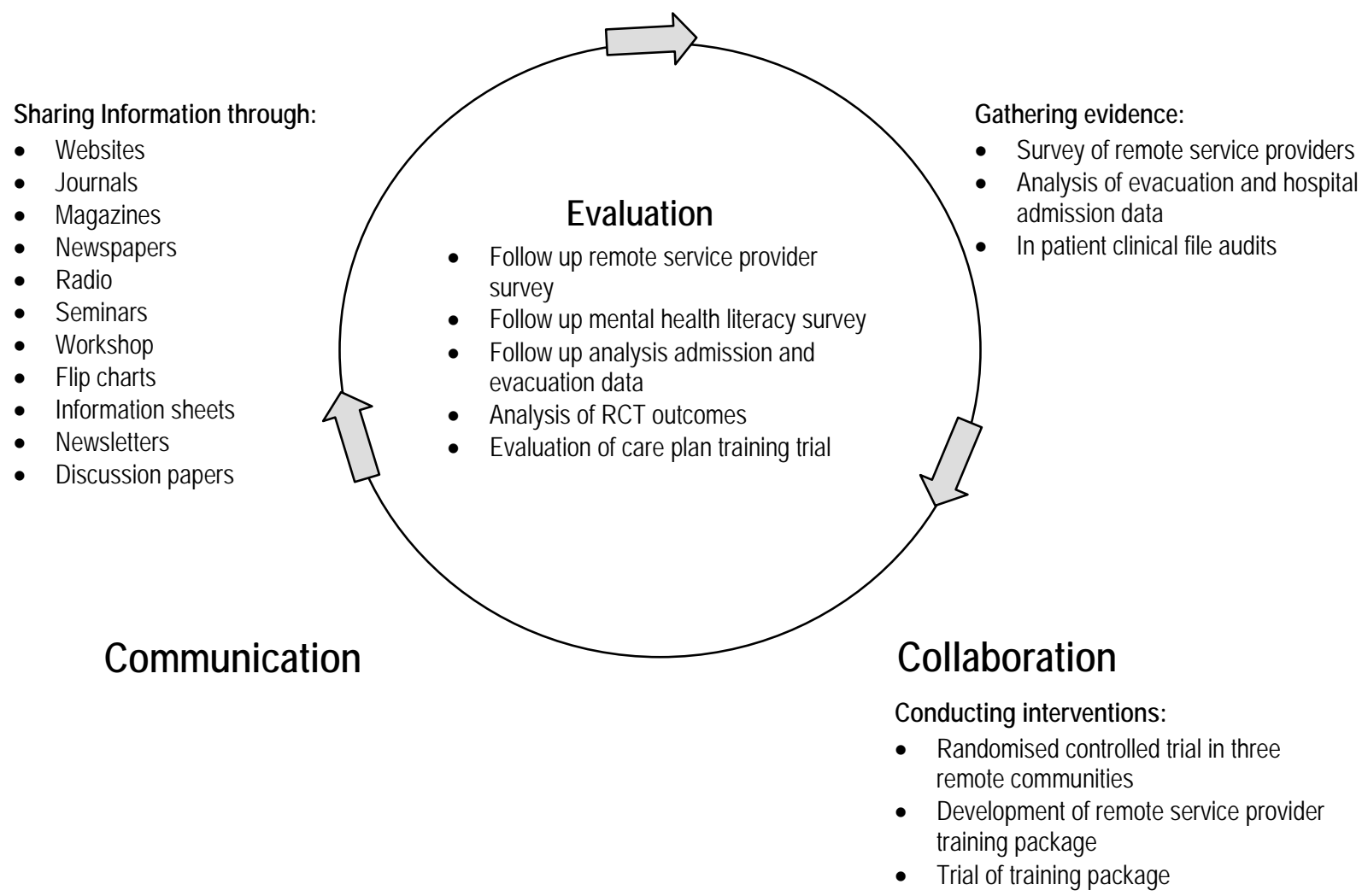

Figure 2. AIMHI interventions in collaboration with stakeholders 2003-2006

to explore the story telling process, and to refine the stories. We also distributed stories through mail outs and publications (flip charts, newsletters, magazines), and invited feedback.

\section{Remote consultation and collaboration}

In the second year, the project commenced a randomised controlled relapse prevention trial in three remote communities, which compares 'treatment as usual' with a care planning treatment and psychoeducation developed using tools created in collaboration with local AMHWs (Nagel, 2005b). The communities were located on remote islands - where most community members still follow traditional cultural activities such as hunting, fishing and ceremony, and speak English as a second language. This provided further opportunity to develop the stories. We began the remote story development by showing short stories that had been developed in the urban setting. We reviewed the content, the photos, and the language in detail with the workers over a number of visits. The urban stories were adapted using photographs, music, artwork and language of that community, and were then translated into video and flip chart formats. We used a hand held digital recorder, a digital camera, and a laptop computer. We incorporated traditional 'healing music' into three of the four stories, and local art and language into new versions of the stories under AMHW direction, using chosen translators where appropriate. We reviewed triggers and stressors, strengths and treatments.

\section{Outcomes}

At completion of the third year of the project we had a number of stories in animated video and laminated flip chart format. They are pictorial, and use traditional healing music and popular music, plain English, Aboriginal English and local language, and blend traditional concepts with western knowledge. A tree with four branches represents the concept of mental health. 
The branches are: spiritual; physical; family, work and social; and mental and emotional - and have four matching root systems. The mental health metaphor talks of nurturing these strong roots to grow a strong well-balanced tree (the 'Grow Strong Tree'). There are three types of story: stories about illness and treatment, stories about the research process, and personal stories about the experience of mental illness. Three of the stories tell of personal journeys of recovery. The stories highlight the importance of culture and traditional activities, and of developing a two way approach to treatment (Indigenous way and non-Indigenous way 'working together'), and describe symptoms of mental illness. The stories have been used in a number of collaborative interventions, such as the psychoeducation component of the randomised controlled trial and the AIMHI remote service provider training (see Figure 2) (ABC Radio National, 2006; Nagel, 2005b, 2006a).

\section{Conclusions}

The story telling project has received positive feedback and encouragement from stakeholders. The feedback has highlighted the important role of incorporating local people and language in sharing information. Symbolism such as the 'Grow Strong Tree' has been well received, and the personal stories have generated much interest. The stories have been used in health promotion, treatment and training. The story telling project has led to development of a multi media package of resources for client and service provider education (Nagel, 2007). The package incorporates a pictorial assessment tool, a pictorial care planning tool, psychoeducation resources and a manual to support assessment and treatment. We have distributed these resources upon request to more than one hundred organisations around Australia. The positive response to the resources has highlighted the need for cross-cultural approaches to sharing mental health information in the remote context. The next phase of the AIMHI NT project is the completion of the relapse prevention trial and commencement of a formal service provider training project. The training package is delivered in flexible workshop formats, either in urban centres or in remote communities. The training has now been delivered to families in remote communities, remote primary care practitioners, mental health professionals, Aboriginal Mental Health Workers and Health Workers, Preventable Chronic Disease nurses, and diabetes educators. Initial feedback suggests that the training improves understanding of mental illness in the Indigenous context for a range of service providers, as well as the broader community. We have received requests for training from services and service providers around Australia. The AIMHI team is training throughout 2007 using these stories, and will report on the evaluation of the training, and the outcomes of the relapse prevention trial, in 2008. There is a need to continue to develop and evaluate strategies for promotion of Indigenous mental health literacy.

\section{Acknowledgements}

The authors gratefully acknowledge the assistance of the AIMHI NT research team, steering committee and Indigenous reference group - especially Robert Mills, Jenni Judd, Valerie Thompson and Neil Spencer, the Tiwi Islands mental health team, and the Top End Division of General Practice, and thank Associate Professor Gary Robinson, Professor Tom Trauer and Dr John Condon for expert advice. The Department of Health and Community Services, the National Health and Medical Research Council and the Cooperative Research Centre for Aboriginal Health support AIMHI NT.

\section{References}

ABC Radio National (2006). Aboriginal Mental Health: Part 1 - Tiwi Islands. Available from www.abc.net.au/rn/allinthemind/stories/2006/165770 $\underline{6 . h t m}$

Australian Bureau of Statistics (2005). The Health and Welfare of Australia's Aboriginal and Torres Strait Islander Peoples (No. 4704.0). Canberra: ABS and AIHW.

Australian Health Ministers Advisory Council's National Mental Health Working Group (1996). National Standards for Mental Health Services. Canberra: Mental Health Branch, Commonwealth Department of Health and Family Services.

Cass, A., Lowell, A., Christie, M., Snelling, P., Flack, M., Marrnganyin, B., \& Brown, I. (2002). Sharing the true stories: Improving communication between Aboriginal patients and healthcare workers. Medical Journal of Australia, 176(10), 466-470.

Clough, A.R., d'Abbs, P., Parker, R., Maruff, P., Gray, D., \& O'Reilly, B. (2004). Emerging patterns of cannabis and other substance use in Aboriginal 
communities in Arnhem Land, Northern Territory: A study of two communities. Drug and Alcohol Review, 23(4), 381-390.

Condon, J.R., Warman, G., \& Arnold, L. (2001). The Health and Welfare of Territorians. Darwin: Epidemiology Branch, Territory Health Services.

Eades, D. (2005). Aboriginal English (Aboriginal Literacy Resource Kit). North Sydney: NSW Board of Studies.

Emotional and Social Wellbeing Working Party (2003). NT Aboriginal Emotional and Social Wellbeing Strategic Plan. Darwin: Northern Territory Aboriginal Health Forum.

Jorm, A.F., Korten, A.E., Jacomb, P.A., Christensen, H., Rodgers, B., \& Pollitt, P. (1997). 'Mental health literacy': a survey of the public's ability to recognise mental disorders and their beliefs about the effectiveness of treatment. Medical Journal of Australia, 166(4), 182-186.

Kirmayer, L., Simpson, C., \& Cargo, M. (2003). Healing traditions: culture, community and mental health promotion with Canadian Aboriginal peoples. Australasian Psychiatry, 11(supplement), S15-S23.

Li, S.Q., Measey M., \& Parker R. (2004). Suicide in the Northern Territory 1981-2002. Darwin: Health Gains Planning, Department of Health and Community Services.

McGorry, P., Killackey, E., Elkins, K., Lambert, M., \& Lambert, T. (2003). Summary Australian and New Zealand clinical practice guidelines for the treatment of schizophrenia. Australasian Psychiatry, 11(2), 136-147.

McLennan, V. \& Khavarpour, F. (2004). Culturally appropriate health promotion: its meaning and application in Aboriginal communities. Health Promotion Journal of Australia, 15(3), 237-239.
Murray, R., Bell, K., Elston, J., Ring, I., Frommer, M., \& Todd, A. (2002). Guidelines for Development, Implementation and Evaluation of National Public Health Strategies in Relation to ATSI Peoples. Melbourne: National Public Health Partnership.

Nagel, T. (2005a). AIMHI NT 2003 Base Line Measures Discussion Paper One. Darwin: Menzies School of Health Research, Institute of Advanced Studies, Charles Darwin University.

Nagel, T. (2005b). AIMHI NT Relapse Prevention Trial. Available from http://clinicaltrials.gov/ct/show/ NCT00192582

Nagel, T. (2006a). Auseinet - Recovery on-line Toolkit. Retrieved July 2006, from http://www.auseinet.com/toolkit/rec_exmpl.php

Nagel, T. (2006b). The need for relapse prevention strategies in Top End remote indigenous mental health. Australian e-Journal for the Advancement of Mental Health (AeJAMH), 5(1), www.auseinet.com/ journal/vol5iss1/nagel.pdf

Nagel T. (2007). AIMHI - Relapse Prevention in Remote Indigenous Mental Health. Available from www.menzies.edu.au/AIMHI

Rickwood, D. (2002). Pathways of Recovery: Preventing Relapse (a discussion paper on the role of relapse prevention in the recovery process for people who have been seriously affected by mental illness). Canberra: Promotion and Prevention Section of the Health Priorities and Suicide Prevention Branch of the Department of Health and Ageing.

Trudgen, R. (2000). Why Warriors Lie Down and Die. Darwin: Aboriginal Resource and Development Services Inc.

World Health Organization (2006). Disease Control Priorities Related to Mental, Neurological, Development and Substance Abuse Disorders. Geneva: World Health Organization. 